Review

\title{
Targeting Alternative Sites on the Androgen Receptor to Treat Castration-Resistant Prostate Cancer
}

\author{
Nada Lallous ${ }^{\dagger}$, Kush Dalal ${ }^{\dagger}$, Artem Cherkasov and Paul S. Rennie * \\ Vancouver Prostate Centre, University of British Columbia, 2660 Oak Street, Vancouver, BC V6H 3Z6, \\ Canada; E-Mails: nlallous@prostatecentre.com (N.L.); kdalal@prostatecentre.com (K.D.); \\ acherkasov@prostatecentre.com (A.C.) \\ $\dagger$ These authors contributed equally to this work. \\ * Author to whom correspondence should be addressed; E-Mail: prennie@prostatecentre.com; \\ Tel.: +1-604-875-4818.
}

Received: 3 May 2013; in revised form: 22 May 2013 / Accepted: 28 May 2013 /

Published: 14 June 2013

\begin{abstract}
Recurrent, metastatic prostate cancer continues to be a leading cause of cancer-death in men. The androgen receptor (AR) is a modular, ligand-inducible transcription factor that regulates the expression of genes that can drive the progression of this disease, and as a consequence, this receptor is a key therapeutic target for controlling prostate cancer. The current drugs designed to directly inhibit the AR are called anti-androgens, and all act by competing with androgens for binding to the androgen/ligand binding site. Unfortunately, with the inevitable progression of the cancer to castration resistance, many of these drugs become ineffective. However, there are numerous other regulatory sites on this protein that have not been exploited therapeutically. The regulation of AR activity involves a cascade of complex interactions with numerous chaperones, co-factors and co-regulatory proteins, leading ultimately to direct binding of AR dimers to specific DNA androgen response elements within the promoter and enhancers of androgen-regulated genes. As part of the family of nuclear receptors, the AR is organized into modular structural and functional domains with specialized roles in facilitating their inter-molecular interactions. These regions of the AR present attractive, yet largely unexploited, drug target sites for reducing or eliminating androgen signaling in prostate cancers. The design of small molecule inhibitors targeting these specific AR domains is only now being realized and is the culmination of decades of work, including crystallographic and biochemistry approaches to map the shape and accessibility of the AR
\end{abstract}


surfaces and cavities. Here, we review the structure of the AR protein and describe recent advancements in inhibiting its activity with small molecules specifically designed to target areas distinct from the receptor's androgen binding site. It is anticipated that these new classes of anti-AR drugs will provide an additional arsenal to treat castration-resistant prostate cancer.

Keywords: androgen receptor; prostate cancer; castration resistance; anti-androgens; protein structure; structure-based drug design

\section{Introduction}

Prostate cancer $(\mathrm{PCa})$ is predicted to be the leading cause of cancer-related death in men over the next decade [1]. In its early stages and when localized to the prostate, this cancer can usually be cured by surgery or radiation therapy. However, for advanced, metastatic or recurrent disease, alternative systemic treatments are required. In this regard, the androgen receptor (AR), a ligand-inducible transcription factor, is considered to be central for PCa development, growth and metastasis [2,3].

The AR belongs to the steroid hormone receptor subfamily of the nuclear receptor superfamily. The human AR is coded by a gene located on the chromosome at Xq11-12 and is composed of 919 amino acids. Similar to other nuclear receptors, the AR is organized into three distinct domains: An $N$-terminal domain (NTD), followed by a DNA binding (DBD) and a $C$-terminal ligand binding domain (LBD) [4,5]. Within this family of receptors, the AR shares most of the sequence similarity with progesterone, glucocorticoid and estrogen receptors [6,7]. Steroidal ligands, principally testosterone and dihydrotestosterone (DHT), bind to a ligand binding pocket on the LBD, called the androgen binding site (ABS), to initiate an activation cascade that results in the transcriptional activation of genes that promote PCa cell viability and growth (for review, see [8]). Accordingly, treatment of advanced prostate cancers usually involves some form of surgical or chemical castration to lower the level of circulating androgens and, thereby, to prevent AR transcriptional activity [9]. In addition, to maximize androgen blockade, PCa patients are often treated with drugs called anti-androgens, which compete with naturally occurring androgens for the receptor's androgen-binding site. Unfortunately, most of these cancers eventually progress to a castration-resistant state, where they no longer respond to androgen deprivation or anti-androgen treatments.

In an attempt to overcome resistance to conventional anti-androgens, computational modeling and high throughput screening techniques have been used to identify small molecules that specifically target functional surface sites of the AR. Several groups have employed this approach to systematically and iteratively optimize small molecules for high-affinity binding to the AR and its effective inhibition [10-15]. The development of such inhibitors has been made possible by investigating the three-dimensional structure of the AR and its co-factors by means of X-ray crystallography, site-directed mutagenesis and biophysical measurements probing the AR's conformational dynamics and interaction with ligands.

It is important to note that rational, structure-based drug design has been used extensively to develop inhibitors for a number of other nuclear receptors, including estrogen- and progesterone 
receptors (ER and $\mathrm{PR}$, respectively), and such efforts have resulted in new anti-cancer drugs (for review, see [16]). These successes have motivated a rational drug discovery approach, guided by protein structure and biochemical experiments, to study protein-ligand interactions of the AR and to develop new types of anti-AR therapies. Herein, we provide a focused review on the structure of the $\mathrm{AR}$ and its functional regions/domains, which can be targeted with small molecules specifically designed to interact with these regions.

\section{Androgen Signaling and AR Function in Early and Advanced Prostate Cancer}

Androgen-dependent gene transcription by the AR is reliant on a long upstream signal transduction cascade, which, in turn, is preceded by a chain of reactions of androgenic synthesis. Since mutations in the AR can substantially affect its transcriptional activity, understanding the AR structure and function in the context of PCa progression requires comprehensive consideration of the entire AR signaling pathway. All androgen-dependent signaling pathways are driven by testosterone produced in the testes and, to a lesser extent, the adrenals [17]. In androgen target tissues, such as the prostate, testicular testosterone is reduced into DHT by $5 \alpha$-reductase - An enzyme that has multiple isoforms in humans, some of which are upregulated in cancer $[17,18]$. DHT is a 10 -fold more potent androgen compared to testosterone and plays a greater role in the progression of prostate enlargement and, ultimately, in tumour development [18].

In the cytoplasm of prostate cells, androgen-free AR is bound by heat shock proteins (HSP) 40, 70 and 90 [19,20], which act as chaperones, maintaining structural integrity of the AR and keeping it in an inactive, ligand-inducible state [19,21]. Upon androgen binding, the AR undergoes conformational changes, which cause a chain of molecular events, including interactions between its $\mathrm{N}$ and $\mathrm{C}$ termini, release of AR-bound HSP proteins and interaction with co-factors, such as importin- $\alpha$, which transports proteins across the nuclear pore complex into the nucleus [22-24] (Figure 1). In the classical understanding of the activation of the AR, its nuclear form is phosphorylated by kinases and interacts as a dimer with androgen response elements (AREs) found in the promoters and enhancers of AR-dependent genes. Recent studies suggest that dimerization of the AR only occurs after nuclear translocation and may require prior binding to the DNA [24] (Figure 1). The majority of transcriptional activity of the AR is believed to be conferred primarily through an activation function (AF1) present in its $N$-terminus region (see Section 3 ) and occurs after recruitment of various factors, including RNA polymerase II and other transcription-initiation proteins [25].

Patients with locally advanced, recurrent or metastatic PCa are usually initially treated with androgen withdrawal therapies, which generally involve either inhibiting androgen synthesis or direct targeting of the AR with anti-androgens, which bind to its androgen binding site. Androgen withdrawal or deprivation consists of reducing the levels of circulating androgens either by surgical castration or by the use of Luteinizing hormone-releasing hormone (LHRH) agonists [26-28]. Although not the subject of this review, a variety of inhibitors that impair androgen synthesis pathways, without direct interaction with the AR, are often used as a second line therapy [29-32]. Among the inhibitors that block key enzymes in the androgen synthesis pathway are ketoconazole, abiraterone, orteronel (TAK-700) and galeterone (TOK-001) [33-38]. Ketoconazole inhibits CYP11 (cholesterol side-chain cleavage enzyme) and CYP17 (17 $\alpha$-hydroxylase/17,20 lyase/17,20 desmolase), members of the 
cytochrome P450 superfamily [33,34]. Abiraterone, orteronel and galeterone are inhibitors of CYP17 [31,35-38]. Abiraterone is currently the main drug used as a second line therapy to block intracrine production of androgens within prostate tumours [35].

Figure 1. The androgen signaling pathway. The androgen receptor (AR) domains are labeled as: $\mathrm{N}-\mathrm{N}$-terminal domain (NTD); D—DNA binding (DBD); L-ligand binding domain (LBD). Locally produced dihydrotestosterone (DHT) interacts with the androgen receptor to facilitate release of heat shock proteins (HSP), N/C dimerization and exposure of a nuclear localization signal (NLS) required for interaction with importin- $\alpha$ and nuclear translocation. Inside the nucleus, the AR exists in equilibrium between monomers and dimers. Although it is unclear which form(s) are required for DNA binding, the AR exists as a dimer when bound to androgen response elements (AREs). DNA binding causes the $\mathrm{N} / \mathrm{C}$ interactions to be lost, allowing the recruitment of transcription initiation and bridging factors, such as CREB binding protein (CBP), the transcription activator p300 and the AR-associated protein 70 (ARA70) to the AR. RNA-Polymerase II (RNAP2) can then transcribe AR-dependent genes.

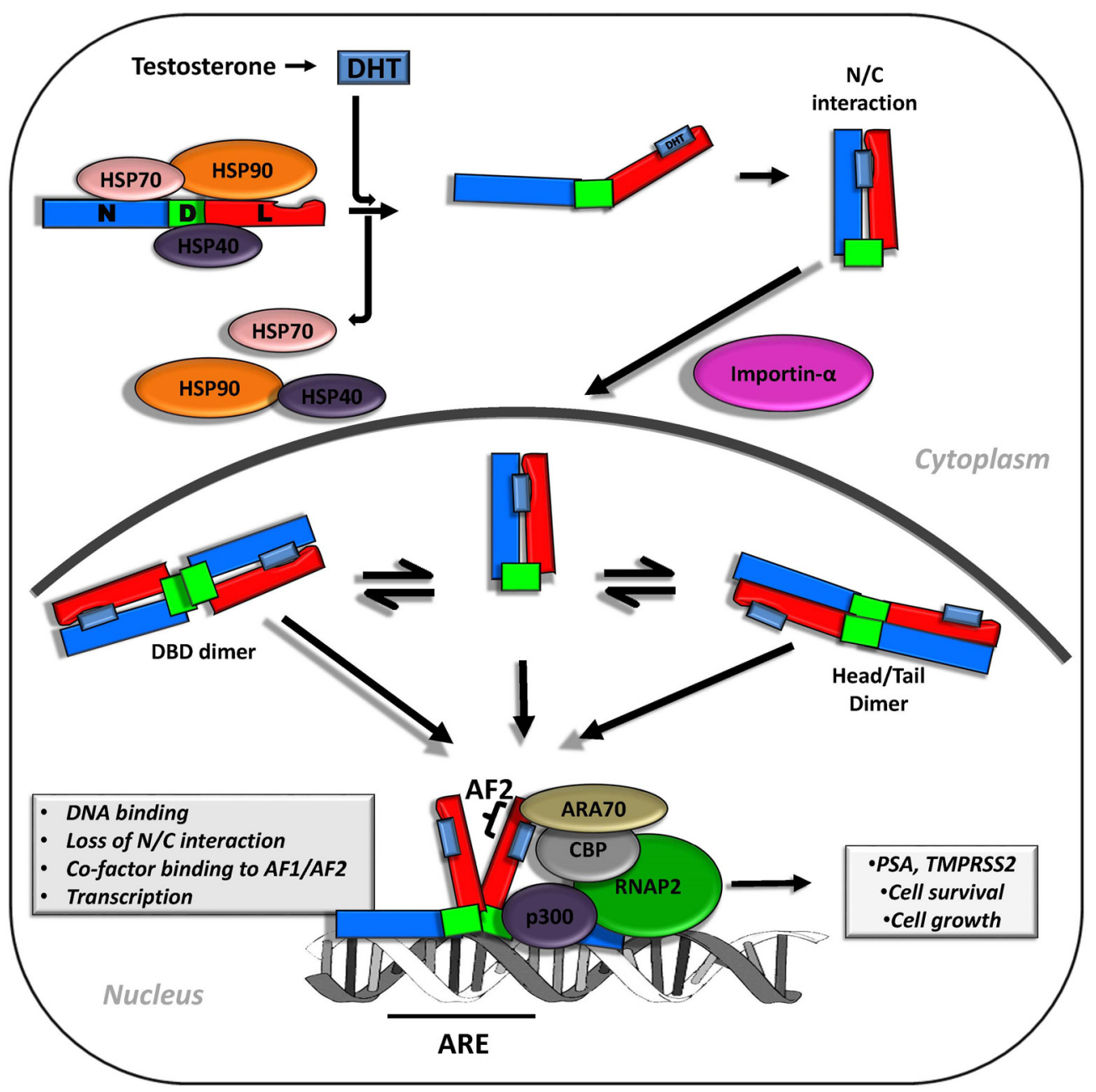

To achieve maximal blockade of androgen signaling, anti-androgens are often used in conjunction with androgen withdrawal therapies [39,40] (discussed in detail in Section 4). Although the exact 
mechanism of action of these compounds remains to be elucidated, competition for the ligand binding site is thought to be the main mode of action and, thereby, prevents nuclear localization of the AR and its activation of transcription (for recent reviews, see [31,41]). While not yet used clinically, RNA interference, using either short hairpin or small interfering RNA (shRNA and siRNA), has been shown to cause tumour regression in PCa xenograft models [42-45].

Although the above methods are initially effective in blocking the AR signaling, patients eventually develop castration-resistant prostate $\mathrm{PCa}$ (CRPC), which is characterized by rising serum prostate specific antigen (PSA) and renewed tumour growth [2,3,46,47], with subsequent poor patient survival [48,49]. Notably, expression of AR-dependent genes, such as PSA and transmembrane protease serine 2 (TMPRSS2), is often reactivated in CRPC, despite low levels of circulating androgens, implying that AR transcriptional activity has become ligand-independent [50]. The recurrence of $\mathrm{AR}$ signaling appears to have multiple origins, further complicating the understanding of mechanisms of CRPC occurrence and progression. Hallmark characteristics of CRPC tumours include, but are not limited to: Increased levels of AR or its mRNA [17,51,52]; somatic mutations in the AR sequence (such as T877A) that convert anti-androgen drugs into agonists [51]; upregulation of enzymes responsible for androgen synthesis [53]; direct alteration of the AR gene [54]; and constitutive transcriptional activity of truncated AR splice variants [55-59] (discussed in Section 3). Comprehensive descriptions and summaries on reported mechanisms of AR reactivation in CRPC can be found elsewhere $[2,54,60]$.

\section{AR Structure and Domain Organization}

\subsection{N-Terminus Domain (NTD)}

The multifunctional role of the AR is implemented through its modular domain organization. The AR $N$-terminus domain (NTD) corresponds to the first 558 residues and contains the AF1 functional region. The NTD is the least conserved domain amongst all nuclear receptors. Accordingly, the EMBOSS metrics [61] demonstrate that the NTD of human AR shares only $8.4 \%$ sequence identity with the human estrogen receptor (ER) NTD, 14.9\% identity in the case of the glucocorticoid receptor (GR) and $21.9 \%$ with the progesterone receptor (PR). The NTD is characterized by the presence of two large repeats, termed homopolymers: Poly-glutamine and poly-glycine fragments, averaging 21 and 24 residues, respectively. The variation in length of the poly-glutamine has been associated with such diseases as X-linked spinal and bulbar muscular atrophy and prostate cancer [62-65]. Other shorter repeats also exist in this AR region, including two poly-glutamine stretches (five to six residues in length), a poly-alanine (five residues), a poly-proline (eight residues) and two amino-acid repeats with the PSTLSL sequence.

The NTD of the AR contains a number of functionally important regions, such that deletion of portions of the NTD or mutation of some of its key residues (such as I229A/L236A; L251A/L254A, M244A, L246A, V248A) can lead to a decrease of AR transactivation activity [66,67]. Furthermore, two transcriptional activation units (TAU) were mapped onto the AR NTD: TAU-1 (residues 101-370) and TAU-5 (residues 360-485) [67,68]. Importantly, the AR-NTD contains an FXXLF motif at residues $23-27$ and a WXXLF motif at residues $433-437$ that are essential for the interaction with the 
AR's LBD. The corresponding contact (termed N/C interaction) has been shown to be critical for stabilizing the androgen in the ligand binding pocket and for overall AR function $[69,70]$.

The AR NTD also plays an essential role in a number of protein-protein interactions $[71,72]$. It has been shown that the NTD serves as a binding site for many transcription machinery components, including TFIIF and TFIIH proteins [73-75], co-activators, such as CREB-binding protein (CBP) [76,77], and co-repressors, like SMRT (silencing mediator for retinoic acid and thyroid hormone receptor) [78]. Despite the importance of the NTD for AR function, currently, there is no structural information available for this domain, in part due to intrinsic disordered regions that compromise the stability of the NTD in solution and prevent its crystallization [72].

\subsection{The DNA Binding Domain (DBD)}

The DBD is highly conserved among NRs. In this regard, the AR DBD shows $79.5 \%$ identity with the corresponding regions of the PR, 71.2\% with the GR and 53.4\% with the ER. This 66 amino acid-long domain contains two zinc finger motifs, where each metal ion is coordinated by four cysteine residues. The first motif contains the $\mathrm{P}$ box (residues 577-581: GSCKV), which interacts with the major groove of the DNA, while the second zinc finger contains the D box (residues 596-600: ASRND), which plays a role in DBD-mediated AR dimerization (Figure 2B) [79]. The AR-DBD recognizes classical androgen response elements (AREs) on the DNA that are organized as inverted repeats of 5'-AGAACA-3'-like motifs with a three nucleotide spacer (IR3) and selective AREs that are considered direct repeats of 5'-AGAACA-3'-like motifs (DR3) [80-82].

There is only one crystal structure available for the rat AR-DBD, which was resolved in a complex with a DR3 response element (PDB: 1R4I) formed by two hexameric half-sites arranged as a direct repeat separated by three base pairs (CCAGAACATCAAGAACAC) [83]. According to the reported crystal structure, the AR-DBD is formed by two short anti-parallel $\beta$-strands and two perpendicular $\alpha$-helices. This organization allows the AR-DBD to bind to the DNA in the form of a "head to head" dimer, where one monomer binds the half-site response element with high affinity and the second binds the other half-site with lower affinity [83].

\subsection{Hinge Region}

The region between the DBD and the LBD (residues 625-689) is flexible and poorly conserved among NRs. The signal responsible for nuclear import is encoded by a bipartite nuclear localization signal (NLS: 617-RKCYEAGMTLGARKLKKL-634) formed by two clusters of basic residues belonging to the $C$-terminus of the DBD and the $N$-terminus of the hinge region [84-86]. The cellular localization of the AR is controlled by androgen binding, such that the AR is cytoplasmic in its ligand-free state, but upon binding of androgen to the LBD, it undergoes a conformational change, which exposes the NLS and facilitates its interaction with importin- $\alpha$, which results in translocation of the activated AR to the nucleus [22,87]. 
Figure 2. Domain organization and available structures of the androgen receptor. (A) Scheme of the domain organization of the AR: NTD ( $N$-terminal domain), DBD (DNA binding domain), $\mathrm{H}$ (hinge region) and LBD (ligand binding domain). Residue numbers above the scheme delineate the domain boundaries; (B) Surface (left) and cartoon (right) representations of the rat AR-DBD structure. Zinc ions are presented as grey spheres, and the D-box of each DBD monomer is highlighted in red. Residues of the P-box involved in DNA recognition are shown as sticks; (C) Surface (left) and cartoon (right) representations of the human AR-LBD structure: surfaces highlighted in cyan and magenta correspond to $\mathrm{AF} 2$ and BF3, respectively. The cartoon representation in yellow corresponds to a coactivator bound to AF2, and the stick representation in green depicts a BF3 small molecule inhibitor. R1881, a synthetic androgen, bound to the androgen binding site, is shown in blue.

A

\begin{tabular}{lc|c|cccc} 
& 558 & 624 & 689 & & 919 \\
\hline & & DBD & H & LBD & \\
\hline
\end{tabular}

B
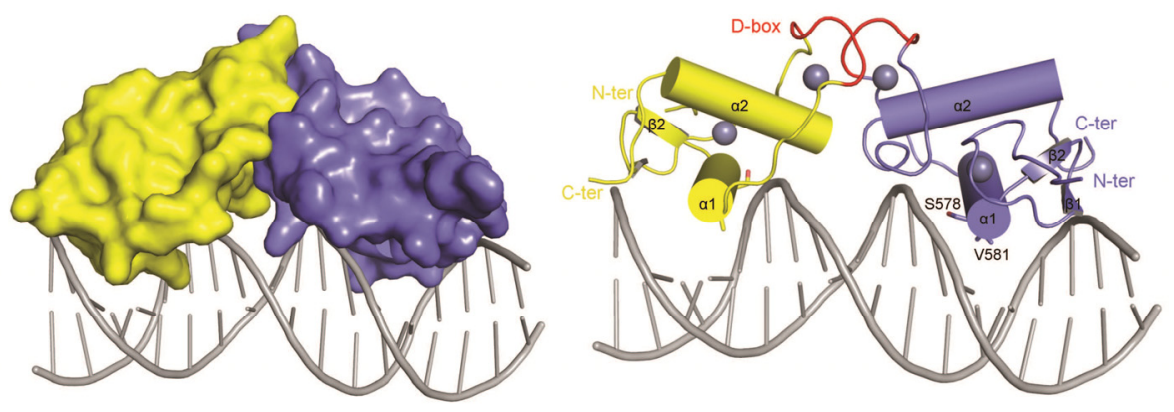

C
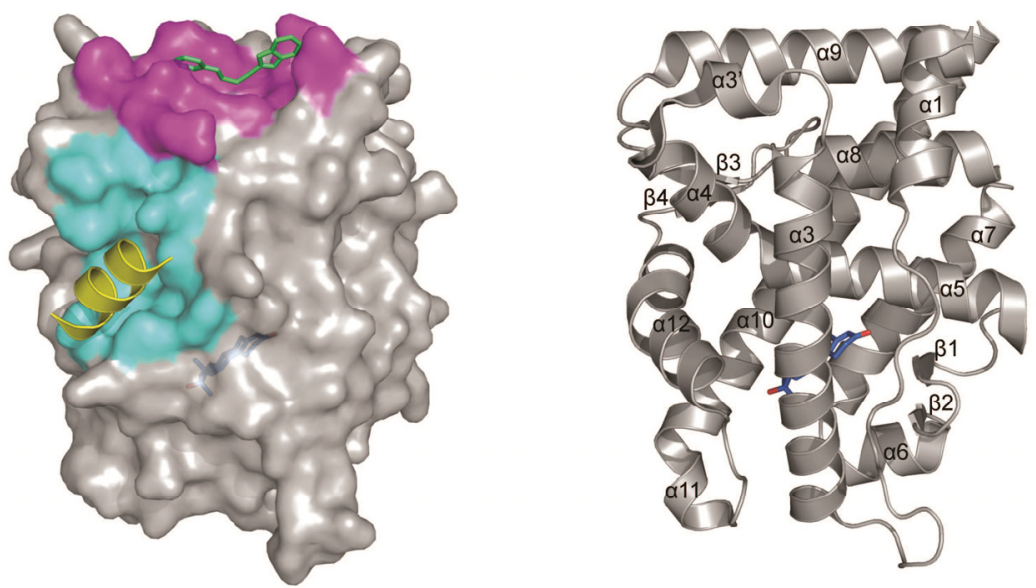


\subsection{Ligand Binding Domain (LBD)}

The LBD is composed of $11 \alpha$-helices (numbered $1-12$, where helix 2 is missing compared to other NRs), arranged as a three-layered helical sandwich and four $\beta$-strands organized in two short sheets (Figure 2C). The androgen binding site of the LBD is formed by residues belonging to $\beta 1$ and helices 3, 5, 7 and 10. These residues make hydrogen bonds and/or hydrophobic interactions with testosterone and DHT moieties [88]. The LBD surface also contains a hydrophobic cleft, known as the Activation Function 2 region (AF2), formed by residues belonging to helices 3, 3', 4 and 12 (Figure 2C). This pocket is structurally completed upon androgen binding, due to induced conformational changes in helix 12 [89]. This movement of helix 12 was captured in the estrogen receptor- $\alpha$ crystal structures resolved for both agonistic and antagonistic forms of the receptor [90]. In the case of the AR, this pocket is a binding site for numerous coactivators, including members of the p160 SRC family, such as steroid receptor coactivator-1 (SRC1), TIF2/GRIP1/SRC2 and SRC3 [91]. Additionally, AR AF2 recognizes, with high affinity, the NTD FXXLF motif to form a strong N/C interaction, essential for AR-dependent gene regulation [69,70,92].

In recent years, an additional surface pocket, called binding function 3 (BF3), was discovered by Dr. Robert Fletterick's group [93]. This site is distinct from the androgen binding and AF2 sites and is believed to allosterically regulate the AF2 [93,94]. The AR BF3 is formed by residues from helices 1 , $3^{\prime}$ and 9 and the loop connecting H3 and H3'regions in the LBD. This surface has been reported to be important for FKBP52-dependent AR regulation; however, no direct binding between the two entities has yet been demonstrated [95]. It has been documented that, in addition to known mutations in the androgen binding site, the AF2 and BF3 areas are also associated with PCa and androgen insensitivity syndromes [96]. Given the importance of these sites for AR function and modulation, they clearly represent prospective targets for developing novel PCa treatments.

\subsection{Splice Variants}

Alternative splicing of RNA transcripts is a mechanism used by cells to increase the diversity of functions of individual genes. The wild-type full length AR consists of eight exons and introns that can be spliced into a plethora of forms, some lacking entire domains (Figure 3). AR splice variants arise primarily through exon skipping and cryptic exon inclusion, where splicing introduces RNA sequences not normally included in the transcript [97]. Although some splice variants, such as AR-45 [98], are found in normal prostate tissue, variants lacking the LBD have been found to be upregulated in tumours (compared to levels in normal prostate cells) [99-102]. In particular, one such truncated form, $\mathrm{AR}-\mathrm{V7} / \mathrm{V} 3$, has been postulated to be a major androgen-independent driver of AR-regulated gene expression in CRPC [55,99,101]. 
Figure 3. Common splice variants of the AR. The AR gene is organized as eight exons, which form the coding sequence for its different domains: NTD - exon 1; DBD - the first and second zinc finger motifs are encoded by exon 2 and 3, respectively; Hinge - exon 4; LBD - exons 5-8. The RNA transcript can by spliced in several ways to include combinations of the standard exons (numbered 1-8), as well as inclusion of cryptic exons (1a, 2a, 3a, 3b). Shown above each splice variant are the corresponding exon numbers included in spliced mRNA. Cryptic exon inclusion results in unique (U) regions with novel nucleic acid sequences not found in the wild-type (WT) AR. In AR-V3/AR6, the inclusion of exon 2 yields a splice variant bearing only one zinc finger $(\mathrm{Zn})$ and, thus, a truncated DBD.

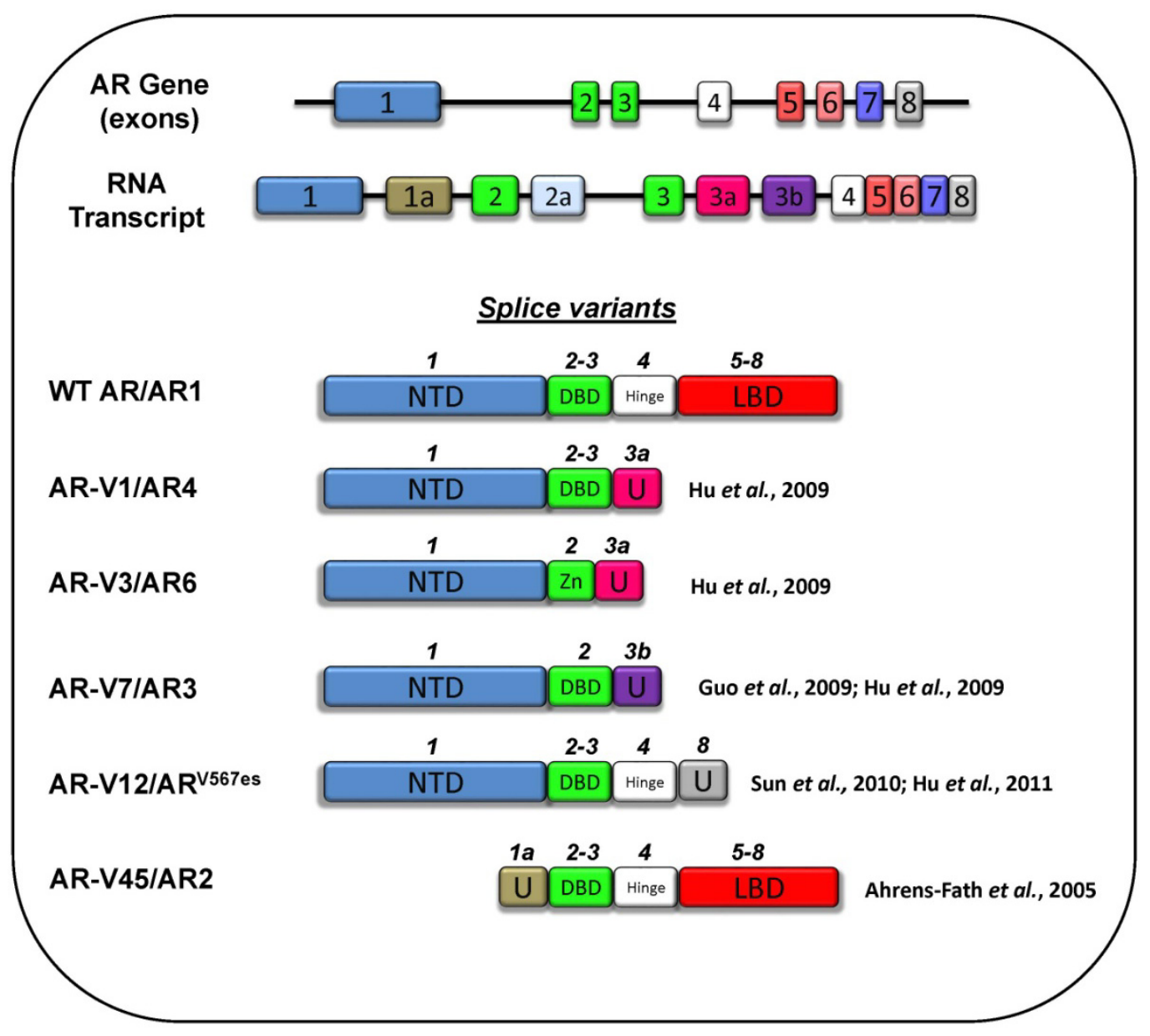

\section{Targeting the LBD}

Most of the current clinically used non-steroidal anti-androgens, including flutamide, nilutamide and bicalutamide (Casodex), target the androgen binding site of the LBD. These drugs compete with endogenous androgens to inhibit AR transcriptional activity. A major complicating factor with continuous treatment using these drugs is the emergence of AR mutations, which can cause resistance or even convert them into AR agonists [103].

Presently, there is no information available on the structure of AR-LBD with bound anti-androgens, due to complications in obtaining a pure LBD/anti-androgen sample suitable for X-ray crystallography. However, different X-ray structures have been solved for the mutated agonist-converting forms of the 
AR-LBD (such as T877A and W741L) in complex with these drugs [104-107]. The pairwise comparison of available crystal structures has revealed that the overall configuration of the AR-LBD in complex with testosterone (PDB: 2AM9) [88], R-bicalutamide (PDB: 1Z95) [104] or hydroxyflutamide (PDB: 2AX6) [105] is highly conserved. The root mean square deviation (RMSD) values calculated for all the backbone chains in the crystal structures are: $0.334 \AA$ (235 $\mathrm{C} \alpha$ ) for $R$-bicalutamide/testosterone and $0.323 \AA$ ( $239 \mathrm{C} \alpha)$ for hydroxyflutamide/testosterone. According to the published structure (PDB: 2AM9), the testosterone molecule establishes hydrogen bonds with R752, N705 and T877 residues and forms a bond with one water molecule (Figure 4A). Hydroxyflutamide and $R$-bicalutamide present the same electrostatic interactions with R752 and N705 side chains (Figure 4B,C). The coordinating water molecule is conserved in all three structures. Additionally, both drugs present extra hydrogen bonds with the main chain nitrogen of V746, due to their fluorine group (F2), with the main chain oxygen of L704 and with an additional water molecule.

Of note, the structure of the T877A AR mutant complexed with hydroxyflutamide presents a new conformation of the W741 side chain (Figure 4B) compared to its conformation in the testosterone structure (Figure 4A). This alternative position of W741 is important to allow a water molecule to establish an additional hydrogen bond with a carbonyl group of hydroxyflutamide and also to accommodate two extra methyl groups from the drug. In the structure of $R$-bicalutamide bound to the W741L AR mutant, the B ring of the ligand occupies the location that was previously filled by the indole ring of the mutated tryptophan. The fluorine group on the B ring forms a hydrogen bond with an additional water molecule. This structural information suggests possible clashes between the antagonists and WT configurations of the LBD, supporting eventual conformational changes or partial unfolding of the AR in the presence of these anti-androgens. This might be due to helix 12 displacement, as was seen with the estrogen receptor- $\alpha$ and the glucocorticoid receptor antagonist structures [108-110].

The anti-androgen enzalutamide (MDV-3100) was recently approved by the FDA for treating metastatic PCa and CRPC. This drug has an $\mathrm{IC}_{50}$ of $21 \mathrm{nM}$, which is an eight-fold higher affinity for the AR compared to bicalutamide $\left(\mathrm{IC}_{50}=160 \mathrm{nM}\right)$ [39], and additionally inhibits $\mathrm{AR}$ nuclear translocation [39,111,112]. No experimental structural information is available on how exactly enzalutamide interacts with the AR, although crystal structures do exist for the AR-LBD in complex with enzalutamide-like agonists (PDB: 3V49 and 3V4A) [113]. Due to the specificity of protein-ligand interactions, more insight into enzalutamide binding to the $\mathrm{AR}$ is needed in order to better understand its antagonistic action.

A more recent experimental anti-androgen, called ARN-509, is structurally similar to enzalutamide and is currently in phase I/II clinical trials [114]. This compound also impairs AR nuclear translocation and DNA recognition by the AR-DBD. Although ARN-509 has the same in vitro behavior as enzalutamide, it shows three-fold better efficacy in CRPC mouse models and has fewer known side-effects [41,114].

Recent advances in the area of rational and computer-aided drug design have resulted in the development of a number of other candidate anti-androgens targeting the androgen-binding site, including compounds, such as 6-(3,4-dihydro- $1 H$-isoquinolin-2-yl)- $N$-(6-methylpyridin-2-yl)nicotinamide (DIMN) [12], its derivatives, termed 7AU and 7BB [115], and 8-(propan-2-yl)-5,6-dihydro-4H-pyrazino[3,2,1-jk]carbazole (MEL-3) [116], all showing promising in vitro and in vivo activities and currently undergoing various stages of pre-clinical development. 
Figure 4. Detailed view of the androgen binding site in complex with (A) testosterone, (B) hydroxyflutamide and (C) R-bicalutamide. The hydrogen bonds and ionic interactions between the protein and the ligand are shown as dashed lines.
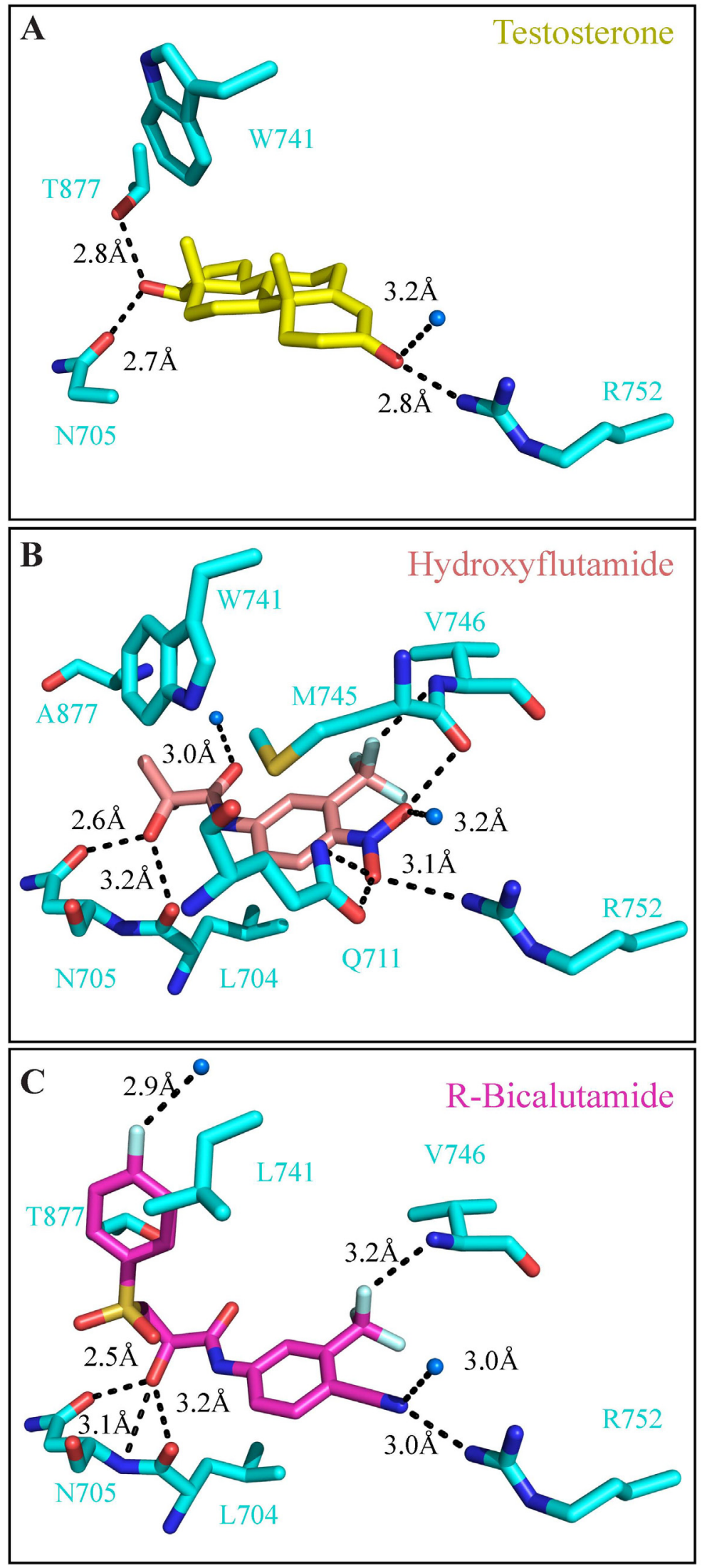
Due to limitations associated with targeting the androgen binding site, finding alternative target areas on the AR has become a major investigational focus. Although the NTD and DBD parts of the protein represent attractive targeting options, (see Section 5 and 6), alternative surface sites on the LBD itself, including the already mentioned AF2 and BF3 functional pockets, remain to be exploited. It is likely that compounds acting on these LBD surfaces would target the receptor by a completely different mechanism compared to conventional anti-androgens, possibly by directly disrupting coactivator recruitment.

Recent studies of compounds designed to bind alternative sites on the LBD surface have shown promising levels of in vitro inhibition of $\mathrm{AR}$ transcriptional activity. In a previous study, Estebanez-Perpina et al. [93] used a fluorescence polarization assay to screen for compounds that bind to the AR AF2 area and that also inhibit its interaction with a SRC2-3 activator peptide. In their screen, they found that two known drugs, triac and flufenamic acid, were able to bind to the AF2 site and block AR transcriptional activity in a cell-based assay (with luciferase reporter). Surprisingly, some of the identified AF2 binding compounds were shown to also bind to the neighboring BF3 surface. The corresponding X-ray structures (PDBs: 2PIX, 2PIU) also highlighted ligand-induced allosteric changes in residues R840, K717 and M734, which form the AF2 site. These changes seemed to be sufficient to disrupt coactivator binding to the AR [94,117].

Our laboratory is also working on targeting the AF2 and BF3 surfaces of the AR in order to develop a new class of inhibitors that can be used alternatively or complementarily to current PCa and CRPC therapies. Using an in silico drug discovery approach integrated with biological validation, we identified several potent small molecule inhibitors selectively targeting the AR AF2 and the $\mathrm{BF} 3$ sites $[10,13,118]$. These compounds were able to inhibit $\mathrm{AR}$ activity with corresponding $\mathrm{IC}_{50}$ values in the sub-micromolar and nanomolar ranges. Furthermore, these proto-drugs also demonstrated inhibition of endogenous PSA expression and secretion in LNCaP PCa cells, as well as effective cell killing in MTS assays. Importantly, the compounds were effective in inhibiting AR activity and causing cell death in enzalutamide-resistant PCa cells [13]. Owing to their distinct AR target sites, there was no apparent cross-resistance observed for the anti-AF2 and anti-BF3 drug prototypes. To validate the on-target binding of these compounds, X-ray structures were resolved with some of the developed inhibitors bound to the AR AF2 or the BF3 sites (PDBs: 2YLP, 2YLO, 2YHD, 4HLW). It is worth noting that AR AF2 and BF3 pockets are highly conserved among NRs, with up to 58\% sequence identity for some family members [117]. Therefore, the cross-reactivity of AF2 and BF3 inhibitors with other NRs should be verified in the future, at least with the most efficient compounds.

\section{Targeting the $N$-Terminal Domain}

The identification of small molecules capable of binding to the AR-NTD has proven to be an elusive goal, given that no structural information is available for this domain. However, since both ligand-dependent and -independent transcriptional activity of the AR is attributed to its $N$-terminal Tau1 and Tau5 regions (see section 3.1), the NTD remains a very attractive drug target for treating both early stage PCa and CRPC. To date, three classes of NTD inhibitors have been reported in the literature: (1) cyclical peptides, termed sintokamides that were isolated from marine sponges; (2) decoy 
peptides containing the AR-NTD sequence; and (3) a small molecule referred to as EPI-001, which is presumed to bind to the AR-NTD and block activating protein-protein interactions of the AR [119].

The peptide-based AR-NTD inhibitor was originally isolated by applying a high-throughput screening approach with a library of natural marine extracts [120]. This led to the discovery of sintokamides, small peptides with varying degrees of chlorination, which were isolated from the marine sponge Dysidea sp. [120]. One such peptide variant, sintokamide A, demonstrated inhibition of the growth of the androgen-dependent $\mathrm{LNCaP} \mathrm{PCa}$ cell line. In addition, sintokamides showed inhibition of transcriptional activity of the NTD fragment of the AR fused to a Gal4 DBD domain (using a luciferase reporter and Gal4 promoter sequence). Since the Gal4-NTD construct has no ligand binding domain, it was suggested that sintokamides are also effective in supressing the AR activity under androgen-independent conditions. A more recent high-throughput screen of extracts from the marine sponge Niphates digitalis has yielded additional candidate compounds that also antagonize AR transcriptional activity [121]. Furthermore, it has been proposed that one such compound, niphatenone B alkynyl ether, may covalently bind to the AF1 region of the NTD [121].

As an alternative approach, a decoy peptide comprising the entire AR-NTD sequence (from amino acid 1 to 538) has been shown to inhibit the transcriptional activity of the full length AR (detected with a PSA reporter construct) [122]. The mechanism of action of the $\mathrm{AR}_{1-538}$ peptide remains unclear, but it likely competes with known AR cofactors for NTD binding. It has also been shown that $\mathrm{AR}_{1-538}$ peptide is effective in both ligand-dependent and -independent conditions. Conceivably, such a decoy peptide may alternatively bind directly to the AF2 of the full length AR, thereby preventing the N/C self-activating interaction facilitated by the FXXLF sequence motif $[123,124]$, which is contained within the first 30 residues of the NTD $[24,123,125]$.

In another study, Andersen et al. [126] reported on the high throughput screening discovery of EPI-001, a small molecule candidate inhibitor for the AR-NTD. This molecule, being a close analog of bisphenol A diglycidic ether, could block transcription of a PSA reporter construct in LNCaP cells. In addition, EPI-001 showed similar activity in 22rv1 cells, which contain both full length AR and the AR-V7 splice variant (Figure 3). Using a PSA reporter construct, EPI-001 was shown to also inhibit the transcriptional activity of a truncated form of the AR lacking the $\mathrm{LBD}$ domain $\left(\mathrm{AR}_{1-653}\right)$. Together, these results suggest that EPI-001 has the capability to directly target the NTD of the AR splice variants. Importantly, the activity of progesterone receptors and glucocorticoid receptors was not affected by EPI-001, which illustrates its specificity for the AR. However, in the absence of the AR-NTD crystal structure, it is unclear how EPI-001 binds to the AR. Nevertheless, intrinsic fluorescence of tyrosine and tryptophan residues within an AF1 peptide could be modulated by this compound, suggesting direct binding to the NTD. Whether EPI-001 binds to the AF1 region within the context of the full length AR remains to be determined. Some support for this interaction was shown by co-immunoprecipitation experiments with the AR, where EPI-001 caused a modest $(21 \%)$ reduction of the pull-down of CBP, a co-factor known to bind to the AR AF1. The inhibitory effect of EPI-001 in vivo was validated by showing a volume reduction in CRPC tumour xenografts in mice. Currently, EPI-001 is the best characterized compound that appears to target and inhibit the activity of the AR-NTD and, therefore, is a good candidate drug for treating CRPC. 


\section{Targeting the DNA Binding Domain}

To date, there has been little progress in the development of AR inhibitors that target the AR-DBD domain [16]. Factors limiting progress in this area of research include high sequence identity between the DBDs of all steroid receptors, which could cause specificity problems for the corresponding AR-DBD-directed compounds. Nevertheless, a recent report using high throughput screening of $\sim 160,000$ molecules identified one relatively AR-specific inhibitor, 1-(3-(2-chlorophenoxy) propyl)-1H-indole-3-carbonitrile, which could potentially interact with the DNA binding domain of the receptor [127]. Chromatin immunoprecipitation experiments indicated that this compound interferes with the binding between the AR and the PSA or TMPRSS2 gene promoters [127]. Western blot analysis also demonstrated that this candidate AR-DBD inhibitor did not affect the level of AR expression. Furthermore, a fluorophore-tagged antibody revealed that the AR was predominantly localized to the nucleus of cells treated with the compound [127]. As a result, it was concluded that 1-(3-(2-chlorophenoxy) propyl)-1H-indole-3-carbonitrile likely targets the AR-DBD in such a way that it modulates AR interaction with DNA. Importantly, using a luciferase reporter assay to measure transcriptional activity, this compound did not affect the GR and showed a modest effect on ER $\alpha$, but only at high concentration [127]. However, additional experiments are needed to demonstrate the direct interaction between this compound and purified AR-DBD.

Development of chemical agents that bind to androgen response element (ARE) sequences to prevent the AR docking onto the DNA has also shown considerable promise. In particular, pyrrole-imidazole (Py-Im) polyamides, sequential arrangements of $N$-methylpyrrole and $N$-methylimidazole carboxamide monomers, may be useful in this regard [128]. Typically, polyamide strands are linked by a $\gamma$-amino acid at one end to generate a hairpin or at both ends to create a cyclical structure. These compounds can specifically interact with the minor groove of DNA and have the ability to bind to G-C or A-T base pairs (depending on the polyamide sequence). In addition, polyamides can allosterically affect the conformation of the double stranded DNA and, thus, prevent protein-DNA interactions [128].

In a recent study, Dervan and coworkers [129] demonstrated that hairpin polyamides could bind to the PSA promoter and downregulate its mRNA expression with the same efficiency as the anti-androgen bicalutamide. Building on these results, Chenowith et al. [130] showed that cyclical polyamides have improved binding to the AREs and can effectively inhibit PSA expression. In mice, polyamides demonstrate favourable cell permeability, high solubility, long half-lives and low toxicity. Recently, a polyamide agent directed against the 5'-NGNNCN-3' sequence of the ARE was tested in mice and shown to lower circulating PSA levels, to activate the p53 gene and to cause apoptotic cell death in LNCaP xenografts [14]. In the presence of this polyamide, the occupancy of RNA polymerase II (RNAP2) onto AR-dependent genes was also reduced, as measured by CHIP-seq analysis. Moreover, Western blots of LNCaP cells treated with this polyamide exhibited marked degradation of the RPB1 subunit, a known elongation factor for RNAP2. Considering all the evidence, Yang et al. [14] suggested that polyamides may weaken the recruitment of RNAP2 to AR specific promoters, resulting in the compromised polymerase elongation. The applicability of polyamides for treating CRPC will depend on the ability of these compounds to simultaneously target multiple AR-dependent genes that have a role in disease progression. Whether a mixture of polyamides designed to specifically target 
different AREs will be effective in downregulating AR transcriptional activity in CRPCs remains to be seen.

\section{Future Outlook}

Understanding the three-dimensional structure and function of AR domains has played a major role in the development of inhibitors against the receptor's transcriptional activity. Whereas most small molecules have been designed to compete with DHT for the androgen binding site in the AR-LBD, additional distinct, yet functionally significant pockets in other regions of the protein, including the BF3 and AF2 surface sites, as well as DBD and NTD domains, should also be targeted to deal with CRPC.

While AR-NTD inhibitors show promise in blocking AR transcriptional activity and treating CRPC tumours driven by AR variants, more detailed information on the structure of the AR-NTD is necessary in order to understand the molecular mechanism of action of small molecule inhibitors, such as EPI-001, as well as peptide molecules, which appear to interact with the AF1 region. At the very least, site-directed mutagenesis of amino-acid residues in the AF1 region should be performed when testing NTD inhibitors to provide evidence that they indeed interact directly at the expected site on the AR.

The AR-DBD may allow for a more rational approach to drug design, given that its crystal structure is already known [83]. In particular, exposed regions at the DBD dimerization (D-box) and DNA binding (P-box) interfaces (Figure 2A) could potentially be targeted by small molecule inhibitors. This will likely require accurate in silico modelling coupled with high throughput screening of small molecules, as well as assessment of their inhibitory effect on AR transcriptional activity using reporter assays. Mutagenesis of key amino-acids in the D-box and P-box weakens the dimerization and transcription factor activity of the AR [24] and clearly shows the importance of these surface exposed regions. Thus, AR-DBD-interfering inhibitors should have the potential advantage of preventing all AR transcriptional activity, including the truncated constitutively active ones, rather than targeting a subset of androgen-dependent genes, such as that achieved using polyamide treatments. It is important to ensure that small molecules directed against the AR-DBD should not cross-react with the DBDs of other nuclear receptors. Presumably, this could be achieved by a detailed comparison of the spectrum of DBD surfaces, while rationally designing the corresponding lead inhibitors. More structural information of the AR-DBD complex with different AREs is now required to validate the underlying mechanisms of DNA binding and dimerization.

The search for new small molecule inhibitors that target alternative pocket sites and surface exposed regions of the AR has intensified considerably in recent years. It has become clear that androgen deprivation and other currently used hormone therapies have inherent limitations, partly due to recent discoveries pertaining to AR splice variants lacking an LBD (e.g., AR-V7) that are implicated in the reactivation of AR signaling in CRPC. Small molecules that target sites on the AR distinct from the androgen binding site are expected to have completely different mechanisms of action for inhibiting AR signaling than conventional anti-androgens and are, therefore, less likely to be cross resistant when used as a second line of therapy. Furthermore, there is a strong potential for these other novel forms of AR inhibitors to be used synergistically with potent clinically used anti-androgens, such as enzalutamide, to achieve a more substantial anti-tumour response. We anticipate that a complete 
picture of the AR structure, using crystallographic, NMR and biochemical methods, will lead to significant drug design breakthroughs in the coming years.

\section{Acknowledgements}

Work in the authors' laboratory is funded primarily by grants from the Canadian Institutes of Health Research (CIHR), Genome BC and a PCF-STAR Project, which is awarded by Prostate Cancer Canada with the support of Canada Safeway. K. Dalal is supported by a CIHR post-doctoral fellowship.

\section{Conflict of Interest}

The authors declare no conflict of interest.

\section{References}

1. Siegel, R.; Naishadham, D.; Jemal, A. Cancer statistics, 2013. CA Cancer J. Clin. 2013, 63, 11-30.

2. Green, S.M.; Mostaghel, E.A.; Nelson, P.S. Androgen action and metabolism in prostate cancer. Mol. Cell. Endocrinol. 2012, 360, 3-13.

3. Sampson, N.; Neuwirt, H.; Puhr, M.; Klocker, H.; Eder, I.E. In vitro model systems to study androgen receptor signaling in prostate cancer. Endocr. Relat. Cancer 2013, doi:10.1530/ERC-12-0401.

4. Hiipakka, R.A.; Liao, S. Molecular mechanism of androgen action. Trends Endocrinol. Metab. 1998, 9, 317-324.

5. Jenster, G.; van der Korput, H.A.; van Vroonhoven, C.; van der Kwast, T.H.; Trapman, J.; Brinkmann, A.O. Domains of the human androgen receptor involved in steroid binding, transcriptional activation, and subcellular localization. Mol. Endocrinol. 1991, 5, 1396-1404.

6. Germain, P.; Staels, B.; Dacquet, C.; Spedding, M.; Laudet, V. Overview of nomenclature of nuclear receptors. Pharmacol. Rev. 2006, 58, 685-704.

7. Eick, G.N.; Thornton, J.W. Evolution of steroid receptors from an estrogen-sensitive ancestral receptor. Mol. Cell. Endocrinol. 2011, 334, 31-38.

8. Lamont, K.R.; Tindall, D.J. Androgen regulation of gene expression. Adv. Cancer Res. 2010, 107, 137-162.

9. Saad, F.; Miller, K. Treatment options in castration-resistant prostate cancer: Current therapies and emerging docetaxel-based regimens. Urol. Oncol. 2013, doi:10.1016/j.urolonc.2013.01.005.

10. Lack, N.A.; Axerio-Cilies, P.; Tavassoli, P.; Han, F.Q.; Chan, K.H.; Feau, C.; LeBlanc, E.; Guns, E.T.; Guy, R.K.; Rennie, P.S.; et al. Targeting the binding function 3 (BF3) site of the human androgen receptor through virtual screening. J. Med. Chem. 2011, 54, 8563-8573.

11. Shen, H.C.; Shanmugasundaram, K.; Simon, N.I.; Cai, C.; Wang, H.; Chen, S.; Balk, S.P.; Rigby, A.C. In silico discovery of androgen receptor antagonists with activity in castration resistant prostate cancer. Mol. Endocrinol. 2012, 26, 1836-1846.

12. Song, C.H.; Yang, S.H.; Park, E.; Cho, S.H.; Gong, E.Y.; Khadka, D.B.; Cho, W.J.; Lee, K. Structure-based virtual screening and identification of a novel androgen receptor antagonist. J. Biol. Chem. 2012, 287, 30769-30780. 
13. Munuganti, R.S.; Leblanc, E.; Axerio-Cilies, P.; Labriere, C.; Frewin, K.; Singh, K.; Hassona, M.D.; Lack, N.A.; Li, H.; Ban, F.; et al. Targeting the binding function 3 (BF3) site of the androgen receptor through virtual screening. 2. Development of 2-((2-phenoxyethyl) thio)-1H-benzimidazole derivatives. J. Med. Chem. 2013, 56, 1136-1148.

14. Yang, F.; Nickols, N.G.; Li, B.C.; Marinov, G.K.; Said, J.W.; Dervan, P.B. Antitumor activity of a pyrrole-imidazole polyamide. Proc. Natl. Acad. Sci. USA 2013, 110, 1863-1868.

15. Voet, A.; Helsen, C.; Zhang, K.Y.; Claessens, F. The discovery of novel human androgen receptor antagonist chemotypes using a combined pharmacophore screening procedure. Chem. Med. Chem. 2013, 8, 644-651.

16. Caboni, L.; Lloyd, D.G. Beyond the ligand-binding pocket: Targeting alternate sites in nuclear receptors. Med. Res. Rev. 2012, doi:10.1002/med.21275.

17. Mohler, J.L.; Gregory, C.W.; Ford, O.H., 3rd; Kim, D.; Weaver, C.M.; Petrusz, P.; Wilson, E.M.; French, F.S. The androgen axis in recurrent prostate cancer. Clin. Cancer Res. 2004, 10, 440-448.

18. Azzouni, F.; Mohler, J. Biology of castration-recurrent prostate cancer. Urol. Clin. 2012, 39, $435-452$.

19. Prescott, J.; Coetzee, G.A. Molecular chaperones throughout the life cycle of the androgen receptor. Cancer Lett. 2006, 231, 12-19.

20. Eichholz, A.; Ferraldeschi, R.; Attard, G.; de Bono, J.S. Putting the brakes on continued androgen receptor signaling in castration-resistant prostate cancer. Mol. Cell. Endocrinol. 2012, 360, 68-75.

21. Centenera, M.M.; Fitzpatrick, A.K.; Tilley, W.D.; Butler, L.M. Hsp90: Still a viable target in prostate cancer. Biochim. Biophys. Acta 2013, 1835, 211-218.

22. Cutress, M.L.; Whitaker, H.C.; Mills, I.G.; Stewart, M.; Neal, D.E. Structural basis for the nuclear import of the human androgen receptor. J. Cell Sci. 2008, 121, 957-968.

23. Kaku, N.; Matsuda, K.; Tsujimura, A.; Kawata, M. Characterization of nuclear import of the domain-specific androgen receptor in association with the importin alpha/beta and Ran-guanosine 5'-triphosphate systems. Endocrinology. 2008, 149, 3960-3969.

24. Van Royen, M.E.; van Cappellen, W.A.; de Vos, C.; Houtsmuller, A.B.; Trapman, J. Stepwise androgen receptor dimerization. J. Cell Sci. 2012, 125, 1970-1979.

25. Heinlein, C.A.; Chang, C. Androgen receptor in prostate cancer. Endocr. Rev. 2004, 25, 276-308.

26. Van der Sluis, T.M.; van Moorselaar, R.J.; Meuleman, E.J.; Ter Haar, R.W.; Bui, H.N.; Heijboer, A.C.; Vis, A.N. Relationship between body mass index and serum testosterone Concentration in patients receiving luteinizing hormone-releasing hormone agonist therapy for prostate cancer. Urology 2013, 81, 1005-1009.

27. Tammela, T.L. Endocrine prevention and treatment of prostate cancer. Mol. Cell. Endocrinol. 2012, 360, 59-67.

28. Liu, S.V.; Liu, S.; Pinski, J. Luteinizing hormone-releasing hormone receptor targeted agents for prostate cancer. Expert Opin. Investig. Drugs 2011, 20, 769-778.

29. Friedlander, T.W.; Ryan, C.J. Targeting the androgen receptor. Urol. Clin. 2012, 39, 453-464.

30. Sadar, M.D. Advances in small molecule inhibitors of androgen receptor for the treatment of advanced prostate cancer. World J. Urol. 2012, 30, 311-318. 
31. Ferraldeschi, R.; de Bono, J. Agents that target androgen synthesis in castration-resistant prostate cancer. Cancer J. 2013, 19, 34-42.

32. Lim, A.C.; Attard, G. Improved therapeutic targeting of the androgen receptor: Rational drug design improves survival in castration-resistant prostate cancer. Curr. Drug Targets 2013, 14, 408-419.

33. Pont, A.; Williams, P.L.; Azhar, S.; Reitz, R.E.; Bochra, C.; Smith, E.R.; Stevens, D.A. Ketoconazole blocks testosterone synthesis. Arch. Intern. Med. 1982, 142, 2137-2140.

34. Lamberts, S.W.; Bons, E.G.; Bruining, H.A.; de Jong, F.H. Differential effects of the imidazole derivatives etomidate, ketoconazole and miconazole and of metyrapone on the secretion of cortisol and its precursors by human adrenocortical cells. J. Pharmacol. Exp. Ther. 1987, 240, 259-264.

35. Fizazi, K.; Scher, H.I.; Molina, A.; Logothetis, C.J.; Chi, K.N.; Jones, R.J.; Staffurth, J.N.; North, S.; Vogelzang, N.J.; Saad, F.; et al. Abiraterone acetate for treatment of metastatic castration-resistant prostate cancer: Final overall survival analysis of the COU-AA-301 randomised, double-blind, placebo-controlled phase 3 study. Lancet Oncol. 2012, 13, 983-992.

36. Zhu, H.; Garcia, J.A. Targeting the adrenal gland in castration-resistant prostate cancer: A case for orteronel, a selective CYP-17 17,20-lyase inhibitor. Curr. Oncol. Rep. 2013, 15, 105-112.

37. Bruno, R.D.; Gover, T.D.; Burger, A.M.; Brodie, A.M.; Njar, V.C. 17alpha-Hydroxylase/17,20 lyase inhibitor $\mathrm{VN} / 124-1$ inhibits growth of androgen-independent prostate cancer cells via induction of the endoplasmic reticulum stress response. Mol. Cancer Ther. 2008, 7, 2828-2836.

38. Ferraldeschi, R.; Sharifi, N.; Auchus, R.J.; Attard, G. Molecular pathways: Inhibiting steroid biosynthesis in prostate cancer. Clin. Cancer Res. 2013, doi:10.1158/1078-0432.CCR-12-0931.

39. Tran, C.; Ouk, S.; Clegg, N.J.; Chen, Y.; Watson, P.A.; Arora, V.; Wongvipat, J.; Smith-Jones, P.M.; Yoo, D.; Kwon, A.; et al. Development of a second-generation antiandrogen for treatment of advanced prostate cancer. Science 2009, 324, 787-790.

40. Schweizer, M.T.; Antonarakis, E.S. Abiraterone and other novel androgen-directed strategies for the treatment of prostate cancer: A new era of hormonal therapies is born. Ther. Adv. Urol. 2012, 4, 167-178.

41. Rathkopf, D.; Scher, H.I. Androgen receptor antagonists in castration-resistant prostate cancer. Cancer J. 2013, 19, 43-49.

42. Liao, X.; Tang, S.; Thrasher, J.B.; Griebling, T.L.; Li, B. Small-interfering RNA-induced androgen receptor silencing leads to apoptotic cell death in prostate cancer. Mol. Cancer. Ther. 2005, 4, 505-515.

43. Cheng, H.; Snoek, R.; Ghaidi, F.; Cox, M.E.; Rennie, P.S. Short hairpin RNA knockdown of the androgen receptor attenuates ligand-independent activation and delays tumor progression. Cancer Res. 2006, 66, 10613-10620.

44. Snoek, R.; Cheng, H.; Margiotti, K.; Wafa, L.A.; Wong, C.A.; Wong, E.C.; Fazli, L.; Nelson, C.C.; Gleave, M.E.; Rennie, P.S. In vivo knockdown of the androgen receptor results in growth inhibition and regression of well-established, castration-resistant prostate tumors. Clin. Cancer Res. 2009, 15, 39-47. 
45. Lee, J.B.; Zhang, K.; Tam, Y.Y.; Tam, Y.K.; Belliveau, N.M.; Sung, V.Y.; Lin, P.J.; LeBlanc, E.; Ciufolini, M.A.; Rennie, P.S.; et al. Lipid nanoparticle sirna systems for silencing the androgen receptor in human prostate cancer in vivo. Int. J. Cancer 2012, 131, E781-790.

46. Sternberg, C.N.; Petrylak, D.P.; Sartor, O.; Witjes, J.A.; Demkow, T.; Ferrero, J.M.; Eymard, J.C.; Falcon, S.; Calabro, F.; James, N.; et al. Multinational, double-blind, phase iii study of prednisone and either satraplatin or placebo in patients with castrate-refractory prostate cancer progressing after prior chemotherapy: The sparc trial. J. Clin. Oncol. 2009, 27, 5431-5438.

47. Molina, A.; Belldegrun, A. Novel therapeutic strategies for castration resistant prostate cancer: Inhibition of persistent androgen production and androgen receptor mediated signaling. J. Urol. 2011, 185, 787-794.

48. Cheng, H.H.; Lin, D.W.; Yu, E.Y. Advanced clinical states in prostate cancer. Urol. Clin. 2012, 39, 561-571.

49. Loriot, Y.; Zoubeidi, A.; Gleave, M.E. Targeted therapies in metastatic castration-resistant prostate cancer: Beyond the androgen receptor. Urol. Clin. 2012, 39, 517-531.

50. Chen, C.D.; Welsbie, D.S.; Tran, C.; Baek, S.H.; Chen, R.; Vessella, R.; Rosenfeld, M.G.; Sawyers, C.L. Molecular determinants of resistance to antiandrogen therapy. Nat. Med. 2004, $10,33-39$.

51. Taplin, M.E.; Bubley, G.J.; Shuster, T.D.; Frantz, M.E.; Spooner, A.E.; Ogata, G.K.; Keer, H.N.; Balk, S.P. Mutation of the androgen-receptor gene in metastatic androgen-independent prostate cancer. N. Engl. J. Med. 1995, 332, 1393-1398.

52. Stanbrough, M.; Bubley, G.J.; Ross, K.; Golub, T.R.; Rubin, M.A.; Penning, T.M.; Febbo, P.G.; Balk, S.P. Increased expression of genes converting adrenal androgens to testosterone in androgen-independent prostate cancer. Cancer Res. 2006, 66, 2815-2825.

53. Montgomery, R.B.; Mostaghel, E.A.; Vessella, R.; Hess, D.L.; Kalhorn, T.F.; Higano, C.S.; True, L.D.; Nelson, P.S. Maintenance of intratumoral androgens in metastatic prostate cancer: A mechanism for castration-resistant tumor growth. Cancer Res. 2008, 68, 4447-4454.

54. Nyquist, M.D.; Dehm, S.M. Interplay between genomic alterations and androgen receptor signaling during prostate cancer development and progression. Horm. Cancer 2013, 4, 61-69.

55. Watson, P.A.; Chen, Y.F.; Balbas, M.D.; Wongvipat, J.; Socci, N.D.; Viale, A.; Kim, K.; Sawyers, C.L. Constitutively active androgen receptor splice variants expressed in castration-resistant prostate cancer require full-length androgen receptor. Proc. Natl. Acad. Sci. USA 2010, 107, 16759-16765.

56. Brand, L.J.; Dehm, S.M. Androgen receptor gene rearrangements: New perspectives on prostate cancer progression. Curr. Drug Targets 2013, 14, 441-449.

57. Dehm, S.M.; Tindall, D.J. Alternatively spliced androgen receptor variants. Endocr. Relat. Cancer 2011, 18, R183-196.

58. Li, Y.; Chan, S.C.; Brand, L.J.; Hwang, T.H.; Silverstein, K.A.; Dehm, S.M. Androgen receptor splice variants mediate enzalutamide resistance in castration-resistant prostate cancer cell lines. Cancer Res. 2013, 73, 483-489.

59. Cao, B.; Liu, X.; Li, J.; Liu, S.; Qi, Y.; Xiong, Z.; Zhang, A.; Wiese, T.; Fu, X.; Gu, J.; et al. 20(S)-protopanaxadiol-aglycone downregulation of the full-length and splice variants of androgen receptor. Int. J. Cancer 2013, 132, 1277-1287. 
60. Lamont, K.R.; Tindall, D.J. Minireview: Alternative activation pathways for the androgen receptor in prostate cancer. Mol. Endocrinol. 2011, 25, 897-907.

61. Rice, P.; Longden, I.; Bleasby, A. Emboss: The european molecular biology open software suite. Trends Genet. 2000, 16, 276-277.

62. Robins, D.M.; Albertelli, M.A.; O’Mahony, O.A. Androgen receptor variants and prostate cancer in humanized AR mice. J. Steroid Biochem. 2008, 108, 230-236.

63. La Spada, A.R.; Wilson, E.M.; Lubahn, D.B.; Harding, A.E.; Fischbeck, K.H. Androgen receptor gene mutations in x-linked spinal and bulbar muscular atrophy. Nature 1991, 352, 77-79.

64. Choong, C.S.; Kemppainen, J.A.; Wilson, E.M. Evolution of the primate androgen receptor: A structural basis for disease. J. Mol. Evol. 1998, 47, 334-342.

65. Davies, P.; Watt, K.; Kelly, S.M.; Clark, C.; Price, N.C.; McEwan, I.J. Consequences of poly-glutamine repeat length for the conformation and folding of the androgen receptor amino-terminal domain. J. Mol. Endocrinol. 2008, 41, 301-314.

66. Betney, R.; McEwan, I.J. Role of conserved hydrophobic amino acids in androgen receptor AF-1 function. J. Mol. Endocrinol. 2003, 31, 427-439.

67. Jenster, G.; van der Korput, H.A.; Trapman, J.; Brinkmann, A.O. Identification of two transcription activation units in the $N$-terminal domain of the human androgen receptor. J. Biol. Chem. 1995, 270, 7341-7346.

68. Reid, J.; Betney, R.; Watt, K.; McEwan, I.J. The androgen receptor transactivation domain: The interplay between protein conformation and protein-protein interactions. Biochem. Soc. Trans. 2003, 31, 1042-1046.

69. He, B.; Kemppainen, J.A.; Wilson, E.M. FXXLF and WXXLF sequences mediate the $\mathrm{NH}_{2}$-terminal interaction with the ligand binding domain of the androgen receptor. J. Biol. Chem. 2000, 275, 22986-22994.

70. He, B.; Wilson, E.M. The NH(2)-terminal and carboxyl-terminal interaction in the human androgen receptor. Mol. Genet. Metab. 2002, 75, 293-298.

71. McEwan, I.J. Molecular mechanisms of androgen receptor-mediated gene regulation: Structure-function analysis of the AF-1 domain. Endocr. Relat. Cancer 2004, 11, 281-293.

72. McEwan, I.J. Intrinsic disorder in the androgen receptor: Identification, characterisation and drugability. Mol. Biosyst. 2012, 8, 82-90.

73. McEwan, I.J.; Gustafsson, J. Interaction of the human androgen receptor transactivation function with the general transcription factor TFIIF. Proc. Natl. Acad. Sci. USA 1997, 94, 8485-8490.

74. Reid, J.; Murray, I.; Watt, K.; Betney, R.; McEwan, I.J. The androgen receptor interacts with multiple regions of the large subunit of general transcription factor TFIIF. J. Biol. Chem. 2002, 277, 41247-41253.

75. Lee, D.K.; Duan, H.O.; Chang, C. From androgen receptor to the general transcription factor tfiih. Identification of cdk activating kinase (CAK) as an androgen receptor $\mathrm{NH}(2)$-terminal associated coactivator. J. Biol. Chem. 2000, 275, 9308-9313.

76. Fronsdal, K.; Engedal, N.; Slagsvold, T.; Saatcioglu, F. CREB binding protein is a coactivator for the androgen receptor and mediates cross-talk with AP-1. J. Biol. Chem. 1998, 273, 31853-31859.

77. Aarnisalo, P.; Palvimo, J.J.; Janne, O.A. CREB-binding protein in androgen receptor-mediated signaling. Proc. Natl. Acad. Sci. USA 1998, 95, 2122-2127. 
78. Dotzlaw, H.; Moehren, U.; Mink, S.; Cato, A.C.; Iniguez Lluhi, J.A.; Baniahmad, A. The amino terminus of the human $\mathrm{AR}$ is target for corepressor action and antihormone agonism. Mol. Endocrinol. 2002, 16, 661-673.

79. Umesono, K.; Evans, R.M. Determinants of target gene specificity for steroid/thyroid hormone receptors. Cell 1989, 57, 1139-1146.

80. Claessens, F.; Alen, P.; Devos, A.; Peeters, B.; Verhoeven, G.; Rombauts, W. The androgen-specific probasin response element 2 interacts differentially with androgen and glucocorticoid receptors. J. Biol. Chem. 1996, 271, 19013-19016.

81. Schoenmakers, E.; Alen, P.; Verrijdt, G.; Peeters, B.; Verhoeven, G.; Rombauts, W.; Claessens, F. Differential DNA binding by the androgen and glucocorticoid receptors involves the second Zn-finger and a $C$-terminal extension of the DNA-binding domains. Biochem. J. 1999, $341,515-521$.

82. Denayer, S.; Helsen, C.; Thorrez, L.; Haelens, A.; Claessens, F. The rules of DNA recognition by the androgen receptor. Mol. Endocrinol. 2010, 24, 898-913.

83. Shaffer, P.L.; Jivan, A.; Dollins, D.E.; Claessens, F.; Gewirth, D.T. Structural basis of androgen receptor binding to selective androgen response elements. Proc. Natl. Acad. Sci. USA 2004, 101, 4758-4763.

84. Zhou, Z.X.; Sar, M.; Simental, J.A.; Lane, M.V.; Wilson, E.M. A ligand-dependent bipartite nuclear targeting signal in the human androgen receptor. Requirement for the DNA-binding domain and modulation by $\mathrm{NH}_{2}$-terminal and carboxyl-terminal sequences. J. Biol. Chem. 1994, 269, 13115-13123.

85. Jenster, G.; Trapman, J.; Brinkmann, A.O. Nuclear import of the human androgen receptor. Biochem. J. 1993, 293, 761-768.

86. Clinckemalie, L.; Vanderschueren, D.; Boonen, S.; Claessens, F. The hinge region in androgen receptor control. Mol. Cell. Endocrinol. 2012, 358, 1-8.

87. Simental, J.A.; Sar, M.; Lane, M.V.; French, F.S.; Wilson, E.M. Transcriptional activation and nuclear targeting signals of the human androgen receptor. J. Biol. Chem. 1991, 266, 510-518.

88. Pereira de Jesus-Tran, K.; Cote, P.L.; Cantin, L.; Blanchet, J.; Labrie, F.; Breton, R. Comparison of crystal structures of human androgen receptor ligand-binding domain complexed with various agonists reveals molecular determinants responsible for binding affinity. Protein Sci. 2006, 15, 987-999.

89. He, B.; Gampe, R.T., Jr.; Kole, A.J.; Hnat, A.T.; Stanley, T.B.; An, G.; Stewart, E.L.; Kalman, R.I.; Minges, J.T.; Wilson, E.M. Structural basis for androgen receptor interdomain and coactivator interactions suggests a transition in nuclear receptor activation function dominance. Mol. Cell 2004, 16, 425-438.

90. Gao, W.; Bohl, C.E.; Dalton, J.T. Chemistry and structural biology of androgen receptor. Chem. Rev. 2005, 105, 3352-3370.

91. Zhou, X.E.; Suino-Powell, K.M.; Li, J.; He, Y.; Mackeigan, J.P.; Melcher, K.; Yong, E.L.; $\mathrm{Xu}, \mathrm{H}$.E. Identification of SRC3/AIB1 as a preferred coactivator for hormone-activated androgen receptor. J. Biol. Chem. 2010, 285, 9161-9171.

92. Wilson, E.M. Analysis of interdomain interactions of the androgen receptor. Methods Mol. Biol. 2011, 776, 113-129. 
93. Estebanez-Perpina, E.; Arnold, L.A.; Nguyen, P.; Rodrigues, E.D.; Mar, E.; Bateman, R.; Pallai, P.; Shokat, K.M.; Baxter, J.D.; Guy, R.K.; et al. A surface on the androgen receptor that allosterically regulates coactivator binding. Proc. Natl. Acad. Sci. USA 2007, 104, 16074-16079.

94. Grosdidier, S.; Carbo, L.R.; Buzon, V.; Brooke, G.; Nguyen, P.; Baxter, J.D.; Bevan, C.; Webb, P.; Estebanez-Perpina, E.; Fernandez-Recio, J. Allosteric conversation in the androgen receptor ligand-binding domain surfaces. Mol. Endocrinol. 2012, 26, 1078-1090.

95. De Leon, J.T.; Iwai, A.; Feau, C.; Garcia, Y.; Balsiger, H.A.; Storer, C.L.; Suro, R.M.; Garza, K.M.; Lee, S.; Kim, Y.S.; et al. Targeting the regulation of androgen receptor signaling by the heat shock protein 90 cochaperone FKBP52 in prostate cancer cells. Proc. Natl. Acad. Sci. USA 2011, 108, 11878-11883.

96. Gottlieb, B.; Beitel, L.K.; Nadarajah, A.; Paliouras, M.; Trifiro, M. The androgen receptor gene mutations database: 2012 update. Hum. Mutat. 2012, 33, 887-894.

97. Guo, Z.; Qiu, Y. A new trick of an old molecule: Androgen receptor splice variants taking the stage?! Int. J. Biol. Sci. 2011, 7, 815-822.

98. Ahrens-Fath, I.; Politz, O.; Geserick, C.; Haendler, B. Androgen receptor function is modulated by the tissue-specific AR45 variant. FEBS J. 2005, 272, 74-84.

99. Guo, Z.; Yang, X.; Sun, F.; Jiang, R.; Linn, D.E.; Chen, H.; Kong, X.; Melamed, J.; Tepper, C.G.; Kung, H.J.; et al. A novel androgen receptor splice variant is up-regulated during prostate cancer progression and promotes androgen depletion-resistant growth. Cancer Res. 2009, 69, 2305-2313.

100. Sun, S.; Sprenger, C.C.; Vessella, R.L.; Haugk, K.; Soriano, K.; Mostaghel, E.A.; Page, S.T.; Coleman, I.M.; Nguyen, H.M.; Sun, H.; et al. Castration resistance in human prostate cancer is conferred by a frequently occurring androgen receptor splice variant. J. Clin. Invest. 2010, 120, 2715-2730.

101. Hu, R.; Dunn, T.A.; Wei, S.; Isharwal, S.; Veltri, R.W.; Humphreys, E.; Han, M.; Partin, A.W.; Vessella, R.L.; Isaacs, W.B.; et al. Ligand-independent androgen receptor variants derived from splicing of cryptic exons signify hormone-refractory prostate cancer. Cancer Res. 2009, 69, 16-22.

102. Dehm, S.M.; Schmidt, L.J.; Heemers, H.V.; Vessella, R.L.; Tindall, D.J. Splicing of a novel androgen receptor exon generates a constitutively active androgen receptor that mediates prostate cancer therapy resistance. Cancer Res. 2008, 68, 5469-5477.

103. Suzuki, H.; Sato, N.; Watabe, Y.; Masai, M.; Seino, S.; Shimazaki, J. Androgen receptor gene mutations in human prostate cancer. J. Steroid Biochem. 1993, 46, 759-765.

104. Bohl, C.E.; Gao, W.; Miller, D.D.; Bell, C.E.; Dalton, J.T. Structural basis for antagonism and resistance of bicalutamide in prostate cancer. Proc. Natl. Acad. Sci. USA 2005, 102, 6201-6206.

105. Bohl, C.E.; Miller, D.D.; Chen, J.; Bell, C.E.; Dalton, J.T. Structural basis for accommodation of nonsteroidal ligands in the androgen receptor. J. Biol. Chem. 2005, 280, 37747-37754.

106. Salvati, M.E.; Balog, A.; Shan, W.; Wei, D.D.; Pickering, D.; Attar, R.M.; Geng, J.; Rizzo, C.A.; Gottardis, M.M.; Weinmann, R.; et al. Structure based approach to the design of bicyclic-1H-isoindole-1,3(2H)-dione based androgen receptor antagonists. Bioorg. Med. Chem. Lett. 2005, 15, 271-276.

107. Duke, C.B.; Jones, A.; Bohl, C.E.; Dalton, J.T.; Miller, D.D. Unexpected binding orientation of bulky-B-ring anti-androgens and implications for future drug targets. J. Med. Chem. 2011, 54, 3973-3976. 
108. Shiau, A.K.; Barstad, D.; Loria, P.M.; Cheng, L.; Kushner, P.J.; Agard, D.A.; Greene, G.L. The structural basis of estrogen receptor/coactivator recognition and the antagonism of this interaction by tamoxifen. Cell 1998, 95, 927-937.

109. Brzozowski, A.M.; Pike, A.C.; Dauter, Z.; Hubbard, R.E.; Bonn, T.; Engstrom, O.; Ohman, L.; Greene, G.L.; Gustafsson, J.A.; Carlquist, M. Molecular basis of agonism and antagonism in the oestrogen receptor. Nature 1997, 389, 753-758.

110. Kauppi, B.; Jakob, C.; Farnegardh, M.; Yang, J.; Ahola, H.; Alarcon, M.; Calles, K.; Engstrom, O.; Harlan, J.; Muchmore, S.; et al. The three-dimensional structures of antagonistic and agonistic forms of the glucocorticoid receptor ligand-binding domain: $\mathrm{Ru}-486$ induces a transconformation that leads to active antagonism. J. Biol. Chem. 2003, 278, 22748-22754.

111. Pal, S.K.; Stein, C.A.; Sartor, O. Enzalutamide for the treatment of prostate cancer. Expert Opin. Pharmacother. 2013, 14, 679-685.

112. Scher, H.I.; Beer, T.M.; Higano, C.S.; Anand, A.; Taplin, M.E.; Efstathiou, E.; Rathkopf, D.; Shelkey, J.; Yu, E.Y.; Alumkal, J.; et al. Antitumour activity of MDV3100 in castration-resistant prostate cancer: A phase 1-2 study. Lancet 2010, 375, 1437-1446.

113. Nique, F.; Hebbe, S.; Peixoto, C.; Annoot, D.; Lefrancois, J.M.; Duval, E.; Michoux, L.; Triballeau, N.; Lemoullec, J.M.; Mollat, P.; et al. Discovery of diarylhydantoins as new selective androgen receptor modulators. J. Med. Chem. 2012, 55, 8225-8235.

114. Clegg, N.J.; Wongvipat, J.; Joseph, J.D.; Tran, C.; Ouk, S.; Dilhas, A.; Chen, Y.; Grillot, K.; Bischoff, E.D.; Cai, L.; et al. ARN-509: A novel antiandrogen for prostate cancer treatment. Cancer Res. 2012, 72, 1494-1503.

115. Yang, S.H.; Song, C.H.; van, H.T.; Park, E.; Khadka, D.B.; Gong, E.Y.; Lee, K.; Cho, W.J. SAR based design of nicotinamides as a novel class of androgen receptor antagonists for prostate cancer. J. Med. Chem. 2013, 56, 3414-3418.

116. Helsen, C.; Marchand, A.; Chaltin, P.; Munck, S.; Voet, A.; Verstuyf, A.; Claessens, F. Identification and characterization of MEL-3, a novel ar antagonist that suppresses prostate cancer cell growth. Mol. Cancer Ther. 2012, 11, 1257-1268.

117. Buzon, V.; Carbo, L.R.; Estruch, S.B.; Fletterick, R.J.; Estebanez-Perpina, E. A conserved surface on the ligand binding domain of nuclear receptors for allosteric control. Mol. Cell. Endocrinol. 2012, 348, 394-402.

118. Axerio-Cilies, P.; Lack, N.A.; Nayana, M.R.; Chan, K.H.; Yeung, A.; Leblanc, E.; Guns, E.S.; Rennie, P.S.; Cherkasov, A. Inhibitors of androgen receptor activation function-2 (AF2) site identified through virtual screening. J. Med. Chem. 2011, 54, 6197-6205.

119. Sadar, M.D. Small molecule inhibitors targeting the "achilles' heel" of androgen receptor activity. Cancer Res. 2011, 71, 1208-1213.

120. Sadar, M.D.; Williams, D.E.; Mawji, N.R.; Patrick, B.O.; Wikanta, T.; Chasanah, E.; Irianto, H.E.; Soest, R.V.; Andersen, R.J. Sintokamides A to E, chlorinated peptides from the sponge Dysidea sp. That inhibit transactivation of the $N$-terminus of the androgen receptor in prostate cancer cells. Org. Lett. 2008, 10, 4947-4950. 
121. Meimetis, L.G.; Williams, D.E.; Mawji, N.R.; Banuelos, C.A.; Lal, A.A.; Park, J.J.; Tien, A.H.; Fernandez, J.G.; de Voogd, N.J.; Sadar, M.D.; et al. Niphatenones, glycerol ethers from the sponge niphates digitalis block androgen receptor transcriptional activity in prostate cancer cells: Structure elucidation, synthesis, and biological activity. J. Med. Chem. 2012, 55, 503-514.

122. Quayle, S.N.; Mawji, N.R.; Wang, J.; Sadar, M.D. Androgen receptor decoy molecules block the growth of prostate cancer. Proc. Natl. Acad. Sci. USA 2007, 104, 1331-1336.

123. Van de Wijngaart, D.J.; Dubbink, H.J.; van Royen, M.E.; Trapman, J.; Jenster, G. Androgen receptor coregulators: Recruitment via the coactivator binding groove. Mol. Cell. Endocrinol. 2012, 352, 57-69.

124. Van de Wijngaart, D.J.; van Royen, M.E.; Hersmus, R.; Pike, A.C.; Houtsmuller, A.B.; Jenster, G.; Trapman, J.; Dubbink, H.J. Novel FXXFF and FXXMF motifs in androgen receptor cofactors mediate high affinity and specific interactions with the ligand-binding domain. J. Biol. Chem. 2006, 281, 19407-19416.

125. Van Royen, M.E.; Cunha, S.M.; Brink, M.C.; Mattern, K.A.; Nigg, A.L.; Dubbink, H.J.; Verschure, P.J.; Trapman, J.; Houtsmuller, A.B. Compartmentalization of androgen receptor protein-protein interactions in living cells. J. Cell Biol. 2007, 177, 63-72.

126. Andersen, R.J.; Mawji, N.R.; Wang, J.; Wang, G.; Haile, S.; Myung, J.K.; Watt, K.; Tam, T.; Yang, Y.C.; Banuelos, C.A.; et al. Regression of castrate-recurrent prostate cancer by a small-molecule inhibitor of the amino-terminus domain of the androgen receptor. Cancer Cell 2010, 17, 535-546.

127. Cherian, M.T.; Wilson, E.M.; Shapiro, D.J. A competitive inhibitor that reduces recruitment of androgen receptor to androgen-responsive genes. J. Biol. Chem. 2012, 287, 23368-23380.

128. Chenoweth, D.M.; Dervan, P.B. Structural basis for cyclic Py-Im polyamide allosteric inhibition of nuclear receptor binding. J. Am. Chem. Soc. 2010, 132, 14521-14529.

129. Nickols, N.G.; Dervan, P.B. Suppression of androgen receptor-mediated gene expression by a sequence-specific DNA-binding polyamide. Proc. Natl. Acad. Sci. USA 2007, 104, 10418-10423.

130. Chenoweth, D.M.; Dervan, P.B. Allosteric modulation of DNA by small molecules. Proc. Natl. Acad. Sci. USA 2009, 106, 13175-13179.

(C) 2013 by the authors; licensee MDPI, Basel, Switzerland. This article is an open access article distributed under the terms and conditions of the Creative Commons Attribution license (http://creativecommons.org/licenses/by/3.0/). 